\title{
Institutional Policies for Scientific Information and Publication
}

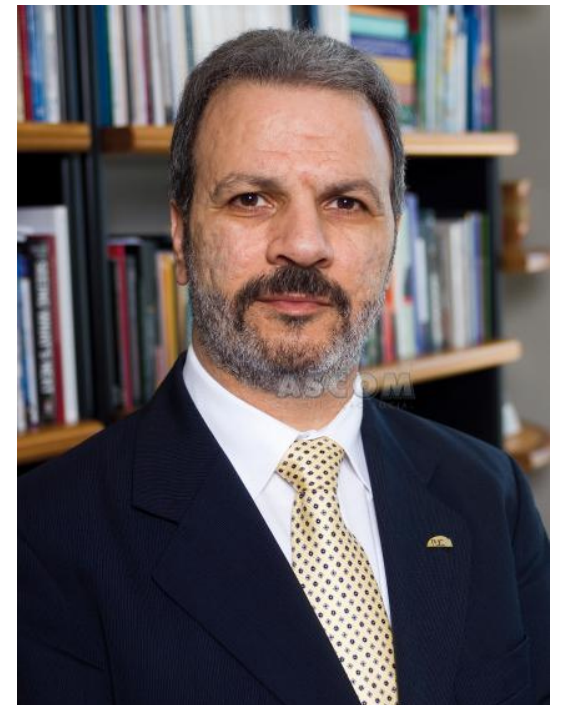

\section{Jorge Audy}

Vice-President for Research and Graduate Studies Professor of the School of Computer Science Pontifical Catholic University of Rio Grande do Sul E-mail: audy@pucrs.br
$C$ Communication and Information is one of the five major program sectors of the United Nations Educational, Scientific and Cultural Organization (UNESCO) to promote inclusion of all people into the knowledge society. Many strategies and courses of action have been designed to facilitate global access to information and knowledge flow for the benefit of research, innovation and socio-economic development across the world. In relation to scientific publications, UNESCO supports open access, i.e., the unrestricted online access to articles published in scholarly journals, conference papers, datasets, learning objects and other e-learning resources. Open access to information and scientific knowledge should benefit not only researchers and innovators but also teachers, students and the general public, contributing to academic freedom and public education.

In Brazil, in May, 2010, the 4th National Conference of Science, Technology and Innovation (ST\&I) for the Sustainable Development (CNCTI) also discussed how both to intensify the actions and initiatives of ST\&I oriented to the general public and to attract more young people to pursue scientific careers. The main challenges and resulting proposals for a government policy of effective ST\&I transfer to society were published in the Livro Azul (Blue Book) by the Center for Strategic Studies and Management in Science, Technology and Innovation (CGEE). This material will feed into national planning on ST\&I in the coming years.
The Pontifical Catholic University of Rio Grande do Sul (PUCRS) has the mission of "generating and spreading knowledge, as well as enhancing humanistic and professional formation, oriented by quality and relevance to develop a fair and fraternal society." Guided by its mission, PUCRS has worked in alignment with national and international directions for the universal advancement of education, ST\&I, socio-economic development and quality of life. One action geared towards public accessibility of high quality scientific information is the open access publication of 29 scientific and academic journals by Edipucrs, the PUCRS University Press.

All online journals published by Edipucrs can be found at the Portal Revistas Eletrônicas da PUCRS, which uses the Sistema Eletrônico de Editoração de Revistas (SEER), a Brazilian translation of the software Open Journal System (OJS). OJS is a journal management and publishing system developed by the Public Knowledge Project (PKP) to expand and improve the scholarly quality of knowledge and the global access to research findings within the open access movement. Therefore, the full-text papers published in the PUCRS online journals of all areas of knowledge can be accessed by both the academic and general public at no cost. The millions of online visits and downloads of these scientific papers since 2005 represent the democratization of high quality scientific information that was peer-reviewed 
and published according to international standards of research integrity and publication ethics.

Besides being indexed in several bibliographic databases and Internet search engines, most electronic PUCRS journals are also available through the Portal de Periódicos da Capes, which celebrated its 10th anniversary in 2010 as the main mechanism of bibliographic support to ST\&I activities in Brazil. In 2009, the number of times the referential bases of this virtual library with approximately 15,000 titles was accessed was over 41.9 million, representing an increase of 3,000\% over ten years (Almeida et al., 2010). Access to this repository of international scientific publications has been fundamental to both the daily work of the Brazilian academic community and the recent advances in national scientific production.

PUCRS will also launch its institutional repository in 2011 to organize, preserve and provide open access to the most relevant academic, scientific and cultural products of the university. The future website of the PUCRS Institutional Repository will provide the general public with access to all indexed material produced at PUCRS. These efforts are being undertaken because it is our social responsibility to provide knowledge in a sustainable and globally accessible form.

\section{Websites of interest}

\section{Reference}

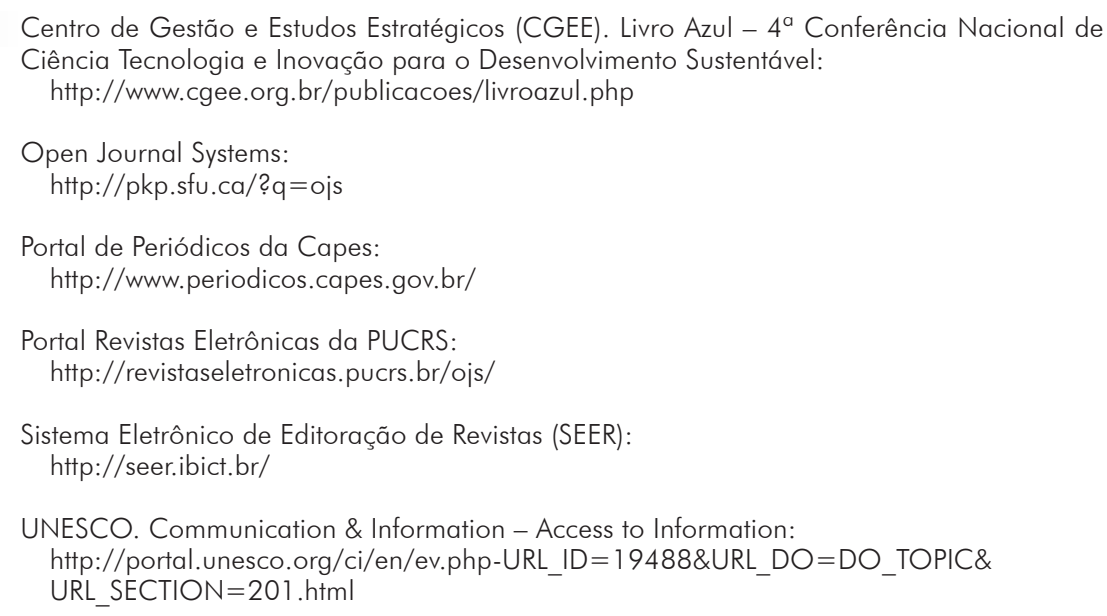

Almeida ECE, Guimarães JA, Alves ITG. Dez anos do Portal de Periódicos da Capes: histórico, evolução e utilização. RBPG 2010;7(13):218-46. 